\title{
SIZE EFFECT IN FRACTURE OF SANDWICH STRUCTURE COMPONENTS: FOAM AND LAMINATE
}

\author{
Zdeň̌k P. Bał̌ant ${ }^{1}$, Yong Zhou ${ }^{2}$, Drahomír Novák ${ }^{3}$ and Isaac M. Daniel ${ }^{1}$ \\ 'Fellow ASME, Walter P. Murphy Professor \\ ${ }^{2}$ Graduate Research Assistant \\ Visiting Scholar, on leave from Bmo Univarsity of Technology, Czech Republic \\ McCormick School of Engineering and Applied Sclence \\ Northwestern University, Evanston, Illinols 60208, USA \\ E-mail: z-bazant@northwestern.edu
}

\begin{abstract}
In the design of sandwich plates and shells for very large structures, such as ships in the range of $100 \mathrm{~m}$ length, it is very important to take the size effect on the nominal strength into account, and do so in a realistic, physically justified, manner. Before the size effect is addressed for a sandwich structure, it must be understood for its components-the foam core and the laminate skins. In the current practice, the size effects are automatically attributed to the randomness of material strength, as described by the Weibull theory. The purpose of this paper is to show that in both the foam and the laminate there are deterministic size effects, which are generally more pronounced. They are caused by stress redistribution and energy release due to the growth of large fractures or large cracking zones prior to attaining the maximum load. This deterministic size effect is verified and calibrated by new tests of notched specimens of rigid close-cell vinyl foam. A combined deterministic-probabilistic theory of size effect of the laminates is proposed and verified by extensive test data.
\end{abstract}

\section{Introduction and Nature of Problem}

The basic property of the classical theories of solid mechanics, particularly plasticity and elasticity with a strength limit, is the absence of size effect, i.e., the nominal strength of a structure (defined, e.g., as the failure load divided by the cross section area) is independent of the characteristic size of the structure. Recently, however, this has been shown untrue when the material does not exhibit plastic yielding [1-3]. In that case, a strong (non-statistical) size effect may be caused by energy release associated with the localization of damage into a finite-size fracture process zone by propagation of large cohesive fractures prior to reaching the maximum load. When this deterministic size effect occurs, it normally prevails over the size effect due to the randomness of strength, described by the classical Weibull theory. Understanding of the size effect is particularly important for extrapolating the results of laboratory testing to large structures, such as large ships whose design is currently of great interest.

In the existing textbooks on composites and sandwich structures, as well as in the current design practice, the deterministic size effect due to the energy release is, unfortunately, ignored. The recent researches at Northwestern University show that this can be dangerous when large structures are designed. In regard to fiber-polymer laminates, which are used for the skins of sandwich structures, it was first shown that when the laminate fails only after a large damage (or fracturing) zone develops, a very strong deterministic size effect is observed in the case of tensile failure [4]. Subsequently, it was shown that the same is true for the compression failure of fiber composites caused by the propagation of a kink band with fiber microbuckling [5]. For both cases, the classical theories exhibit no size effect, but are acceptable only for very small structures. For the design of sandwich structures to be used in the construction of large ships, the mastering of the fracture and scaling properties is very important. The purpose of this paper is to report new results on this complex problem obtained as part of a project on failure of sandwich structures at Northwestern University. The results involve new experiments as well as reinterpretation of previous experimental studies.

The sandwich structures, because of their very low stiffness/weight and strength/weight ratios, represent a very effective structural system for large ships. The sandwich structures have been investigated systematically since the $1950 \mathrm{~s}$. The early researches have led to excellent understanding of the elastic deformations and stability, and particularly the role of high shear deformability of the light polymer foam cores, which distinguishes the sandwich-type from homogeneous plates and shells [6-11]. Later, the 
inelastic behavior and failure characteristics of sandwich structures have been studied by many researchers [12-20]. Several basic mechanisms of failure have been identified [21-24]. The skins of a sandwich may fail by buckling delamination with fracture or by buckling triggered by indentation. They may also fail by quasi-plastic extension with distributed damage or by compression or tensile fracture of the skin. The core may fail by plastic yielding or by fracture. The overall failure may be triggered by any one of these mechanisms, and a complete failure typically involves a combination of failures in both the core and the skins.

A difficult aspect of sandwich failure is the development of distributed damage and its localization. This phenomenon has been shown to cause large deterministic size effects in other quasibrittle materials, and by analogy the same must be expected for sandwich structures. With this motivation, a microplane constitutive model for a rigid closed-cell polymeric foam and a finite element model for the nonlinear failure behavior of a sandwich plate have been developed at Northwestern University [25-26]. The computed load-deflection curves of a sandwich beam exhibited a distinct deterministic size effect. However, quantitative predictions of failure behavior and size effect for a broad size range would make little sense because the quasibrittle fracture properties of the material are not known adequately.

For a realistic prediction of the size effects and scaling of failure of sandwich structures, one must first obtain experimental information and mathematical models for the size effects in the components. Therefore, attention has now been focused first on the size effect in the basic components, which are, (1) the fiber-composite laminates which are used for the skins, and (2) the rigid closed-cell polymeric foam which is used for the core. The purpose of this article is to report progress in both fronts of inquiry.

\section{Deterministic Size Effect and Quasibrittle Fracture Properties of Foam}

Tensile fracture tests of single edge-notched prismatic specimens of closed-cell polymeric rigid foam (Divinycell 100) have been carried out. All the specimens had the same thickness $b=25.40 \mathrm{~mm}$. To determine the size effect, specimens geometrically similar in two dimensions of various depth, $D=6.35$, $43.94,304.80 \mathrm{~mm}$ (Fig. 1a), were made, with a constant length-to-depth ratio 5:2. Notches of width 1.00 $\mathrm{mm}$ and depth $0.4 \mathrm{D}$ were cut with a band saw. The tip of the notch was made sharp by a blade having the thickness of $0.25 \mathrm{~mm}$. The ends of specimens were glued by epoxy to very stiff steel platens which were gripped in the loading machine, with any rotation of the ends prevented. The specimens were loaded in an Instron- 8500 testing machine in tension (Fig. 1b). To avoid the viscoelastic effects due to differences in the loading rate, the displacement rate of the platens was uniform throughout the test and was chosen such that the specimens of any size would reach the maximum load within about 5 minutes. Displacements were measured by LVDT gages mounted across the notch mouth (Fig. 1b) spanning a base length of $11.50 \mathrm{~mm}$.

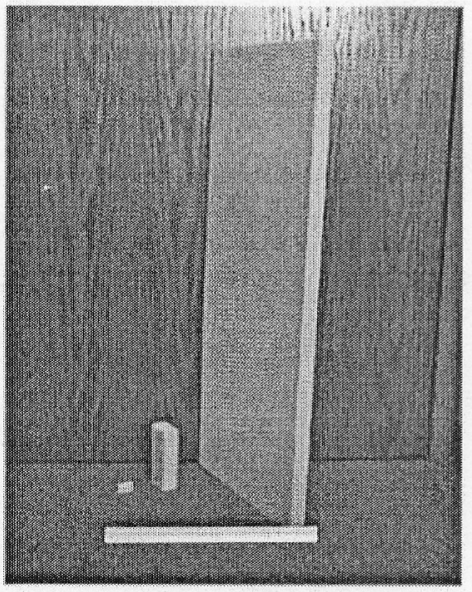

(a)

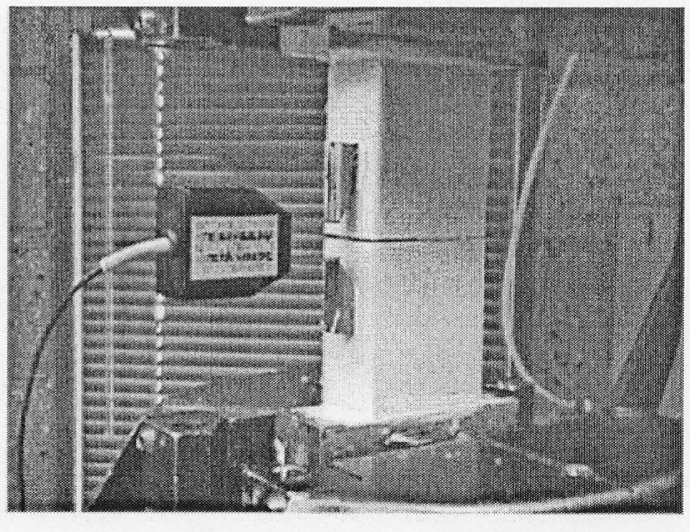

(b)

Fig. 1 (a). Foam Specimens geometrically similar in two dimensions for tensile fracture test(Divinycell $\mathrm{H} 100$ ); (b). Test set-up for a median size specimen in tensile fracture test. 
The measured curves of load versus end displacement are shown in Fig. 2a. The nominal strengths of the individual specimens, $\sigma_{N}=P_{\max } / b D$, as functions of the characteristic specimen size, $D$ (taken as the specimen depth), are plotted in logarithmic scales in Fig. $2 b$. Now it should be noted that if the foam behaved in a ductile manner, following the theory of plasticity, the size effect plots in Fig. $2 \mathrm{~b}$ would have to be horizontal. The fact they are not proves that there is a size effect, in fact a very strong size effect.

If, on the other hand, the foam obeyed linear elastic fracture mechanics (LEFM), the logarithmic size effect plot would have to be a straight line of downward slope $-1 / 2$, shown in Fig. 2b. The results are very close to that line, which means that on the scale of the tests the material behaves in an almost brittle manner. The term 'brittle' is understood as the adherence to LEFM, while the term "quasibrittle" refers to nonlinear cohesive softening fracture behavior deviating from LEFM (the cohesive plastic, or nonsoftening, fracture behavior, with a plastic yielding zone in front of the crack tip, is termed "brittleductile").

Note that if the nominal strength obeyed Weibull theory of size effect, the plot of $\log \sigma_{N}$ versus $\log D$, corresponding to the typical values of Weibull modulus, would have to be a straight line of a slope much less than that of the data in Fig. $2 \mathrm{~b}$. This is evidently not the case.

According to the size effect method of measuring nonlinear fracture properties [27, 28], the location in Fig. $2 \mathrm{~b}$ of the asymptote of slope $-1 / 2$ determines the fracture energy $G_{f}$ of the material, and the rate at which this asymptote is approached determines the effective size of the fracture process zone, $c_{f}$, representing the distance from the actual crack tip to the tip of an equivalent LEFM crack for which the best fit of the actual size effect curve is obtained. From $c_{f}, G_{f}$ and elastic modulus $E$, one can also determine the fracture toughness, $K_{C}=\sqrt{E G_{f}}$, and the critical crack-tip opening displacement, $\delta_{C T O D}=\left(8 G_{f} c_{f} / E\right)^{1 / 2} / \pi$ introduced for fracture of metals by Cottrell [29] and Wells [30].

Although a rigorous derivation of the size effect method can be given on the basis of the $J$-integral and asymptotic expansions in terms of a power series in $\theta=c_{f} / D$, let us sketch a brief and simple derivation from equivalent LEFM. From the conditions that the energy release rate $G=G_{f}$ and that the derivative of $G$ with respect to crack length vanishes at maximum load, one obtains for the nominal strength the well known expression:

$\sigma_{N_{*}}=\sqrt{E G_{f} / D g(\alpha)}$

in which $g(\alpha)=k^{2}(\alpha)=$ dimensionless energy release rate of the specimens, $k(\alpha)=$ dimensionless stress intensity factor, $\alpha=a / D, a=$ crack length. For fracture situations of positive geometry (increasing $g$ ), which includes the present tests, the fracture process zone at maximum load is attached to the notch tip, and so $a=a_{0}+c_{f}$ or $\alpha=\alpha_{0}+\theta$ where $a_{0}=a / D, \theta=c_{f} / D$, and $c_{f} \approx$ half-length of the fracture process zone [28]. Introducing the approximation $g(\alpha)=g\left(\alpha_{0}+c_{f}\right)=g\left(\alpha_{0}\right)+g^{\prime}\left(\alpha_{0}\right) c_{f}$, one gets

$\sigma_{N}=\sqrt{\frac{E G_{f}}{\left[g^{\prime}\left(\alpha_{0}\right) c_{f}+g\left(\alpha_{0}\right)\right] D}}=\frac{\sigma_{N_{0}}}{\sqrt{1+D / D_{0}}}$

in which $D_{0}=c_{f} \frac{g^{\prime}\left(\alpha_{0}\right)}{g\left(\alpha_{0}\right)}, \quad \sigma_{N 0}=\sqrt{\frac{E G_{f}}{c_{f} g^{\prime}\left(\alpha_{0}\right)}}$

Here $D_{0}$ represents the transitional size delineating the brittle behavior from nonbrittle behavior and corresponds to the intersection of the asymptotes in Fig. $2 b ; D_{0}$ and $\sigma_{N_{0}}$ are constant because, owing to geometric similarity, $\alpha_{0}$ is a constant for all the specimens tested. The foregoing expressions for $\sigma_{N}$ can be easily fit to the test data, either by nonlinear optimization (Levenberg-Marquardt algorithm) or by linear regression if Eq. (2) is reaarranged to an expression for $\sigma_{N}{ }^{-2}$ as a function of $D$, which represents a linear regression plot (Fig. 2c). The optimum fit, in the least-square sense, is shown by the curve in Fig. 2b. From the optimum values of $D_{0}$ and $\sigma_{N_{0}}$, one can identify $G_{f}$ and $c_{f}$, and from these values the other fracture properties. The results for the present foam are:

$G_{f}=0.61 \mathrm{~J} / \mathrm{mm}^{2}, \quad c_{f}=0.33 \mathrm{~mm}, \quad K_{c}=10.27 \mathrm{~N} \mathrm{~m}^{-3 / 2}, \quad \delta_{\text {CrOD }}=0.37 \mathrm{~mm}$ 
Knowledge of these parameters makes it possible to analyze the fracture of the core in a sandwich plate by cohesive crack model or crack band model. This approach is of course applicable only if the maximum load is reached only after a large stable crack growth (when the crack at maximum load is only microscopic, another deterministic size effect law applies and a Weibull-type size effect may be expected to be present for large sizes).
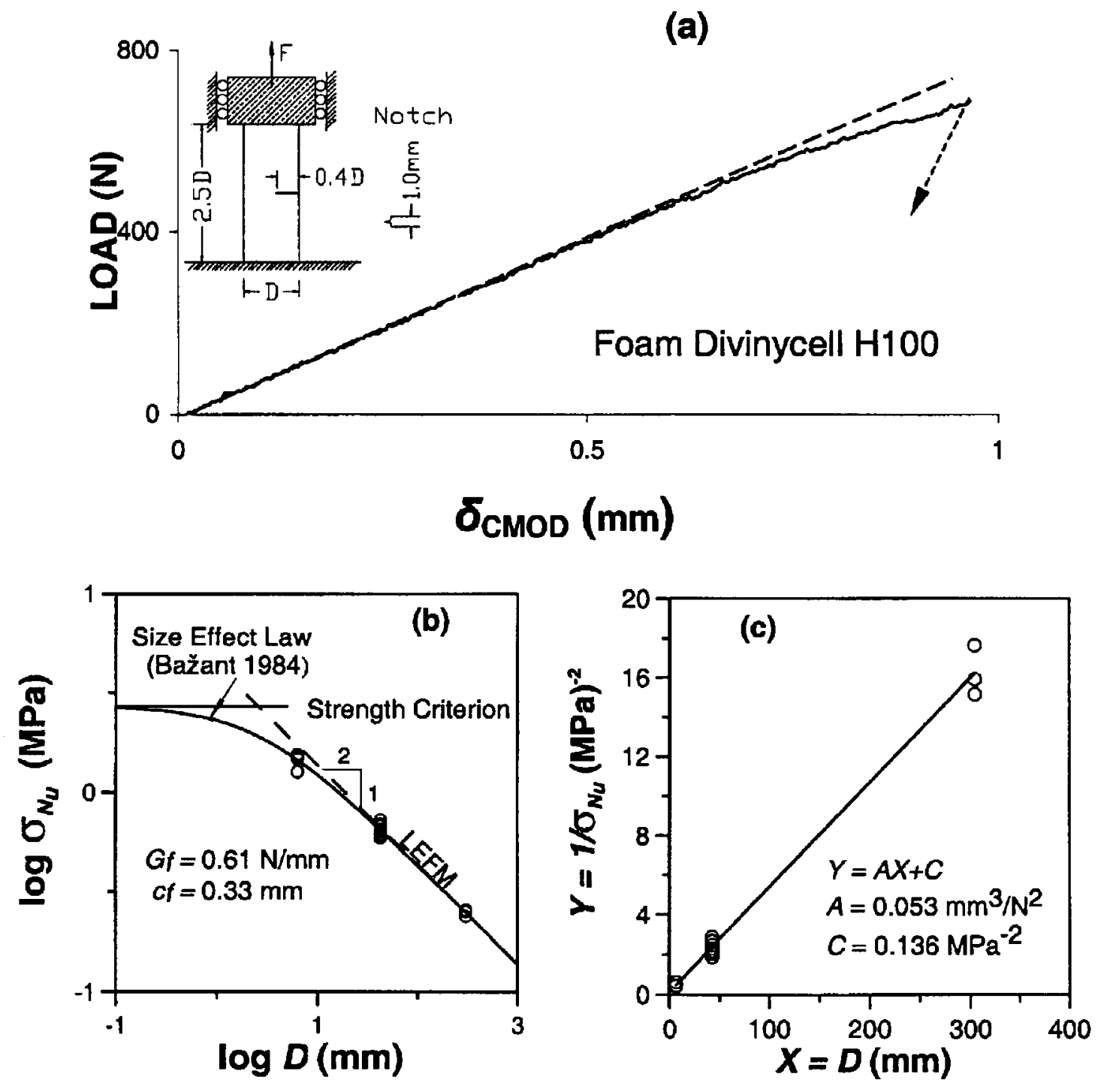

Fig. 2 (a). A typical load- $\delta_{\text {cmoo }}$ curve in the tensile fracture test. (b). Results of tests of nominal strength of geomelrically similar prismatic Divinycell foam specimens with similar one-side notches subjected to tension, as function of specimen size D. (c). Linear regression based on equation (2). 


\section{Energetic Size Effect on Flexural Strength of Laminates}

Calculations of delamination of the skin of a sandwich structure require the knowledge of flexural strength of the laminate used for the skins. Therefore, the size effects on the strength of laminates have been investigated. While the previous studies at Northwestern University dealt with the size effect on the nominal strength of fiber-composite laminates containing a large crack or notch, or a kink band $[4,5]$, the present study is focused on the flexural strength (or modulus of rupture) of laminate without any macroscopic crack or notch.

The size effects on the tensile, compressive and flexural strength of fiber composite laminates containing no notch nor crack prior to maximum load have been investigated intensely [31-35]. However, all these studies assumed a priori that the size effect is purely statistical, as described by Weibull theory of random local strength of a material $[36,37]$. Recently, though, it has been established $[38,39]$ that this theory is valid only if (1) the structure has a positive geometry (i.e., the energy release function is increasing, rather than decreasing, with the crack extension), and if (2) the failure of a microscopic material element causes the whole structure to fail, as described by the weakest link model [40-42]. The Weibull theory describes very well the failure of fine-grained ceramics and fatigue-embritted metals but, as transpired recently, not the heterogeneous quasibrittle materials [28]. For such materials, the energy release caused by the stress redistributions due to the growth a fracture is a potent source of size effect.

For the sake of simplicity, we consider the cross section of laminate to be homogeneous, in which case the elastic bending stress diagram is linear (Fig. 3). As a crucial assumption of our analysis, we note that the peak bending moment $M_{0}$ is not reached when the elastically calculated bending stress at tensile face reaches the material strength $f_{t}$. Rather, before reaching $M_{0}$, a zone of a certain finite thickness $2 D_{b}$ that is a property of the fiber composite is assumed to develop at tensile face, causing stress redistribution and energy release.
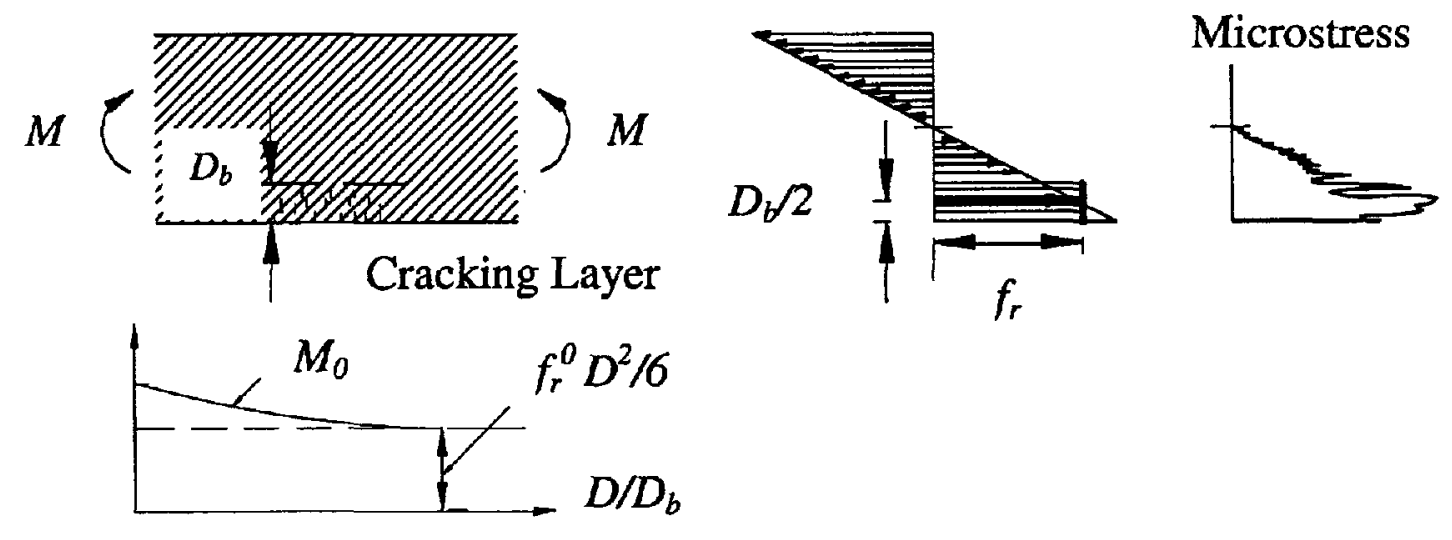

Fig. 3 Stress redistribution due to boundary layer of cracking.

The simplest way to take this into consideration (with an accuracy up to the first two terms of the power series expansion in terms of $1 / D$ ) is to consider that $f_{r}^{0}$ is approximately decided by the average elastically calculated stress within the boundary layer of thickness $2 D_{b}$. Consequently, from the bending stress formula, $f_{r}^{0}=M_{0}\left(D-D_{b}\right) / 2 I$ where $D=$ beam depth, $M_{0}=$ bending moment, and $I=D^{3} / 12$. Noting that the flexural strength of a laminate (or modulus of rupture), $f_{r}$, chosen to represent the nominal strength, is defined as the elastically calculated maximum stress in the beam, $f_{r}=\sigma_{N}=M_{0} D / 2 I$, we obtain $\sigma_{N}=f_{r}^{0}\left(1-D_{b} / D\right)^{-1}$. This formula, however, is acceptable only for $D \gg D_{b}$; it gives a negative $\sigma_{N}$ for small $D$. It can be shown that this formula is correct only up to the first two terms of the asymptotic series expansion in terms of the powers of $1 / D$ [43]. Therefore, any other formula that exhibits the same first two asymptotic terms is equally justified. This observation suggests the use of asymptotic matching, which is a technique to obtain an approximate solution for problems in which the extreme situations are much easier to solve, by interpolating' between the opposite extremes, corresponding here to $D \rightarrow 0$ and $D \rightarrow \infty$ [44-46]. In this spirit, we need to modify the formula such that the first two terms of the large-size asymptotic expansion would be unaffected while a realistic small-size solution is matched. 
It misy be checked that by making the replacement $\left(1-D_{b} / D\right)^{-1}=(1+r D b / D)^{1 / r}(r$ being any puxilive constagt), the first two terms of the aymptotic expansion in terms of $1 / D$ are not atfected while at the same time $\sigma_{H}$ becomes positive, finite and monatonically decreasing through the entire range of $D$. This leads to the size effect fox tonula [47]:

$\sigma_{H}=f_{Y}=f_{Y}^{D} \psi(D), \quad q(D)=\left(1+\frac{r D_{P}}{D}\right)^{\frac{1}{r}}$

where $g(D)$ is a positive dimensionless decreasing tunction of size $D$ having a findte limit for $D \rightarrow \infty$.

A more realistic starting hypothesis is to consider thal, up to the maximum load, the cracking remuins distributed (the discrete crack being formed only at, or after, the maximum load), and that the cracking is described by a biliness stress-strain diagram with postpeak sureis-soflening charocterized by tangent modulus $\boldsymbol{E}_{1}$. The distributed cracking at maximum loud is assumed to occupy a boundary layer at tenajle surface, hoving a certain fixed thlekness denoted by $l$. The cortesponding stress distribution is sketched

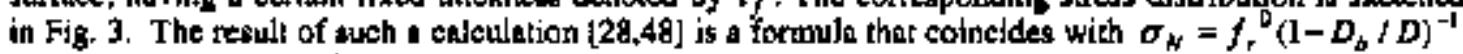
up to the second leme of the asyenptutic expansion of $\sigma_{N}$ as a power series in $1 / D$, provided thol ons exs $l_{f}=D_{b} / 2$, differences being found only in the third ard higher terms.

A more general and more fundamental approach is an asymptocic unalysls based on axpanding the concy relase function of fructure mechanics. It was pursued in [38, 39]. As far as the first two lerms of the asymptotic expension of the vise effecl are concerned, the resuts of such analysis happens to be again the same, except that s sljght offecl of specimen geometry is brought in through $g(\alpha)$,

$A$ further generalization may be achieved wib the formula:

$\sigma_{N}=f_{r}^{D} q(D), \quad q(D)=\left(1+\frac{r D_{b}}{D+r D_{b}}\right)^{\frac{1}{r}}$

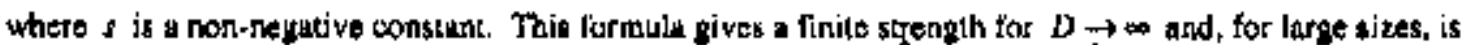
ayain asymptotically equivalent to the oxiginal [urmula $\sigma_{N}=f_{\mathrm{r}}\left(1-D_{b} / D\right)^{-1}$ up to the secord tercin of power series axpansion in $I / D$. One can verify it by tho following approximations, whlch is aceurate up to the second torm of the asymptotic power sories in terms of $\xi$, with $\xi=D_{0} / D$;

$\frac{f_{r}^{0}}{\sigma_{\mu}}=\left[\frac{1+r \xi \xi}{1+r(s+1) \xi}\right]^{L / r}-\frac{1+5 \xi}{1+(s+1) \xi} *(1+s \xi)[1-\{s+1) \xi] * 1+\frac{D_{b}}{D}$

\section{Combined Energetic-Stutlstlical Słze Eftect un Fiexural Strenght of Laminates}

In the case that the maximum berding moment is govorned by the tencile strength, the randomness of locid strength can amplify the sizs olfect on the mean nominal sisength. A gereral and fundamental approach to the combined energetic-statisticul size effect is the nonlocal Weibull theory [38], in which the material failure probability at a gives point of the body does not depend on lie stress at that poinl but on the weighted average of strain within a certain charecteristic volume af material sumpunding the poinl. This theory heb bexn uad in numcrical studies of flexural fajlum [39] from which it transpired that the size effect for very thin plates is almost totally energetic (deteministic) and for very thick platen elmost tolally statistical, of Weibull type. These two esymptotic conditions muy be satisfied by the following simple aize effect formula:

$\sigma_{H}=f_{z}^{0}\left[\left(\frac{D_{b}}{D+r s D_{b}}\right)^{r n_{t} / m}+\frac{r D_{b}}{D+r s D_{b}}\right]^{\frac{1}{r}}$

where $n_{d}=$ number of spatid dimensions in which the structure is scaled $\left(n_{d}=1,2\right.$ or 3 ), $m=$ material constant $=$ Weibull roodulus. For lack of precise and brotd test data, the value of $s$ cannot be determined experimentaily and therefore we assume $s=0$. Note that for $m \rightarrow \infty$ (and $s=0$ ) one resuvers the 
foregoing energetic (deterministic) formula, while for $D_{b}=0$ (and $s=0$ ) one recovers the classical formula for Weibull size effect. (Experience with concrete, however, showed that the statistical part of the size effect on flexural strength is significant only for extremely thick structures such as dams.)

\section{Reinterpretation of Previous Experimental Studies of Size Effect in Laminates}

To check and calibrate the energetic-statistical theory of flexural strength of laminates, a systematic study of the numerous test data that exist in the literature has been initiated [31-35]. One data set that has already been evaluated is that recently reported by Jackson [31]. This data set involves apparently the broadest size range, with the laminate thickness ranging from $1 \mathrm{~mm}$ to $6 \mathrm{~mm}$. The specimens geometrically similar in three dimensions were constructed of a high-modulus graphite-epoxy (AS4/3502) composite prepreg material. The laminate stacking sequence includes unidirectional, cross-ply, angle-ply and quasiisotropic arrangements. The testing method was unusual: Very slender and long laminate strips were loaded by axial force causing them to buckle, with deflections of the order of the specimen length.

The axial shortening and force were measured but the maximum deflections, unfortunately, were not. However, it may probably be assumed that the specimens behaved almost linearly up to failure. Under that assumption, the deflection curve is the well-known 'elastica', for which the ordinates may be solved by elliptic integrals in a manner due to Kirchhoff [49] and thus the bending moment at failure assessed. Calculation of the elastica was exploited in $[50,51]$ for developing a very simple testing method of longtime (multi-year) stress relaxation in polymeric laminates. In this method constant (which was possible because of the linearity of viscoelastic behavior), a laminate strip was strongly bent and its ends mounted at supports on a fixed base that kept the chord length of the arc. The axial force was measured at periodic intervals as the force needed to effect a very small shortening displacement between the ends. The results were translated into bending moments by a calculation of the elastica. A table was calculated from the elliptic integrals for this purpose (see Table 1). The same table has presently been used for calculating the maximum bending moments in Jackson's bent strips from the reported end displacements (chord shortenings), assuming elastic behavior up to the peak load. From these bending moments, the flexural strength $\sigma_{N}$ was calculated for each tested specimen.

Table 1. Geometrical Properties of Elastica

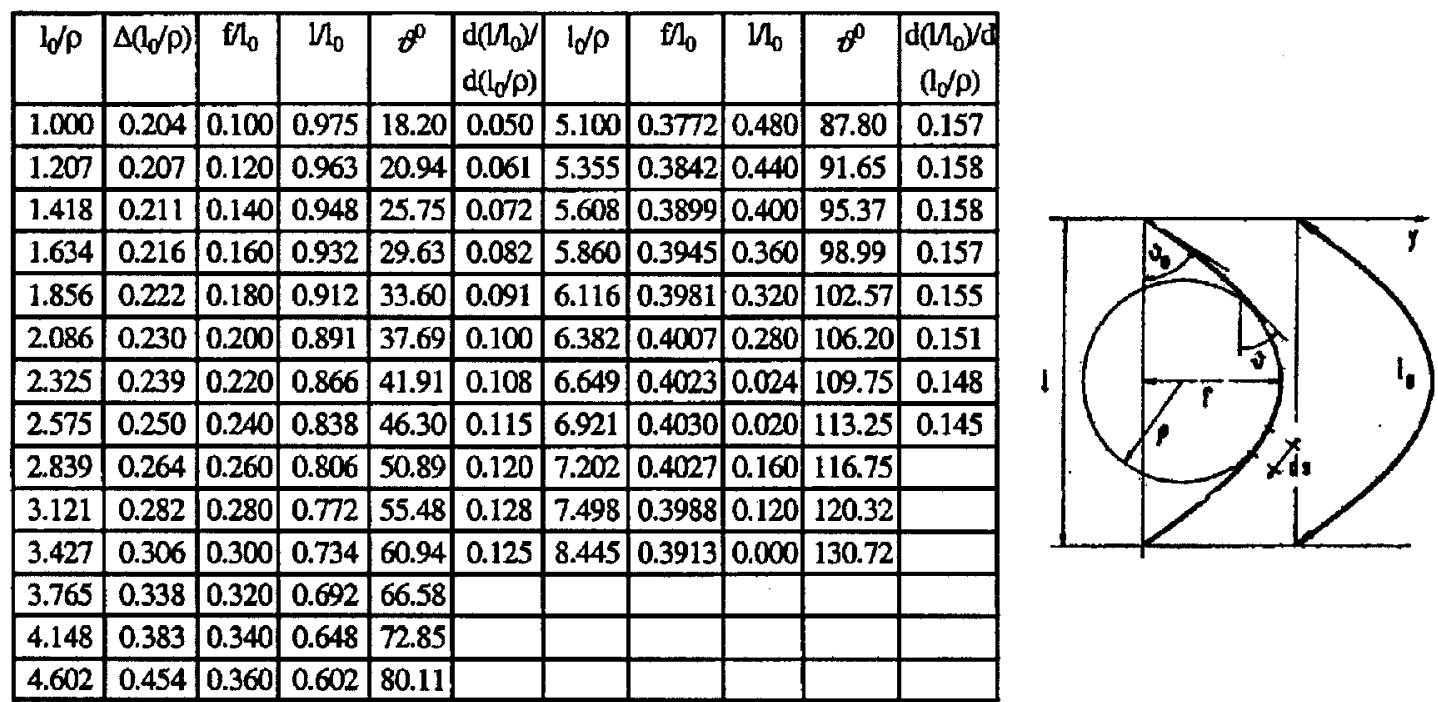

The results of these calculations are shown in Figs. 4 and $S$ in logarithmic plots of flexural strength $\sigma_{N}$ (modulus of rupture) versus laminate thickness $D$. The data are first fit separately for unidirectional, crossply, angle ply and quasi-isotropic laminates, and the energetic (deterministic) formula is fit to each of these data (Fig. 5). This yields the optimum values of constants $D_{b}$ and $f_{r}^{0}$ for each case. Then the relative strengths $\sigma_{N} / f_{r}^{0}$ are plotted versus the relative size $D / D_{b}$, where the values of $f_{r}^{0}$ and $D / D_{b}$ are 
different for each case. It is seen that these data agree with the energetic formula very well (see Fig. 4a, where $\omega$ is the coefficient of variation).

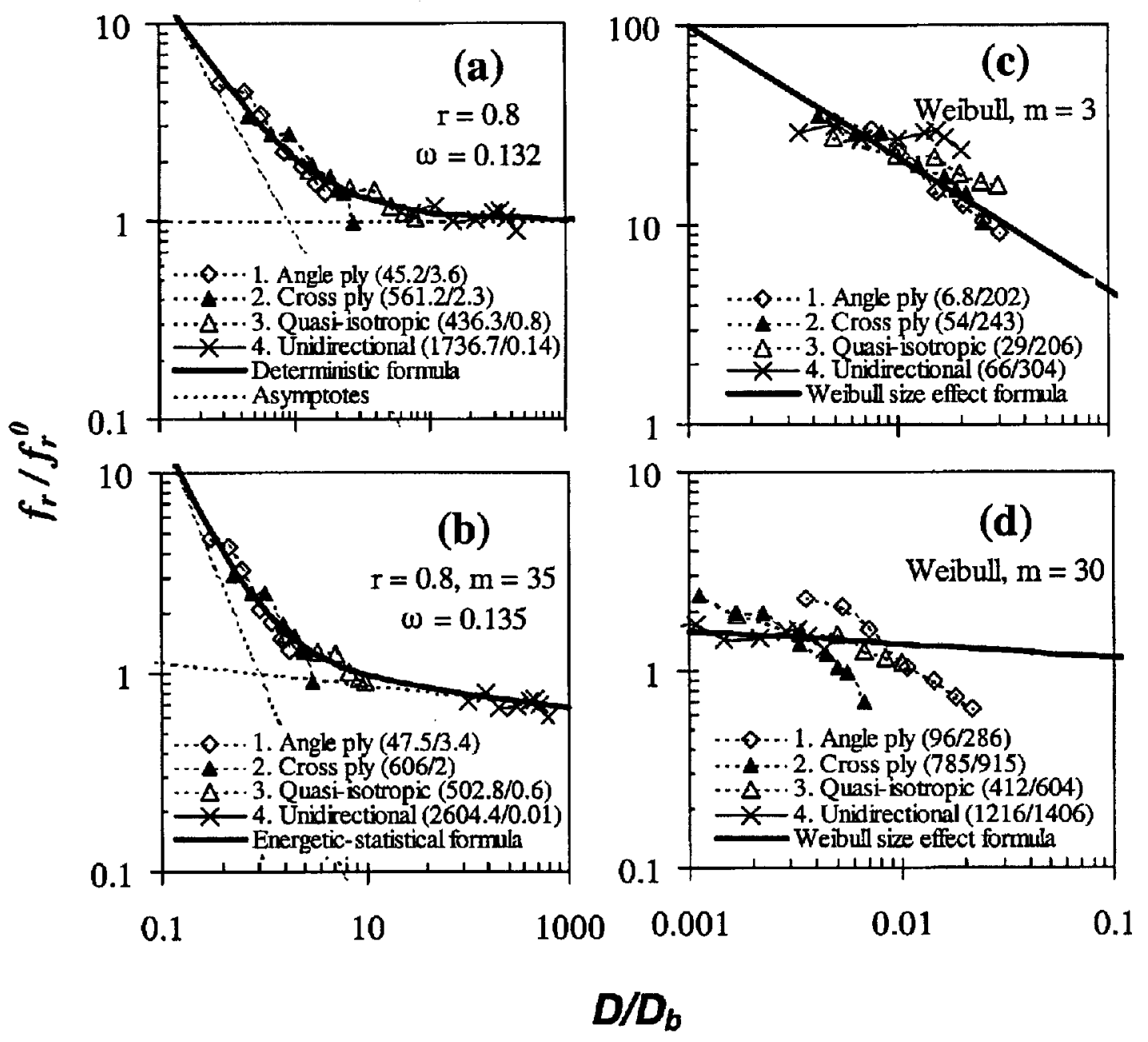

Figure 4. Optimum fit of Jackson's [31] data on modulus of rupture versus relative size in dimensionless coordinates. (a) Deterministic-energetic formula. (b) Energetic-statistical formula. (c) Weibull size effect formula with $m=3$. (d) Weibull size effect formula with $m=3$ (to save space, the label such as $(45.2 / 3.6)$ means $f_{f}^{\circ}=45.2 \mathrm{MPa}$ and $D_{b}=3.6 \mathrm{~mm}$, and similar for all labels).

Subsequently the same fitting procedure is repeated with the general energetic-statistical formula. The resulting fit is shown in Fig. 4b. As can be seen, an improvement is hardly noticeable on this set of data; $\omega$ is nearly the same as in the previous case. Nevertheless broadening the size range to much thicker laminates would be likely to bring about considerable improvement.

Finally, the same data are plotted using only the Weibull statistical size effect formula, $\sigma_{N}=f_{r}^{0}\left(D_{b} / D\right)^{n_{d} / m}$. The resulting fits are shown in Figs. $4 \mathrm{c}$ and $4 \mathrm{~d}$ for very different value of $m$. It is seen that the match of these data with the statistical theory is poor in the overall plot. The value $m=3$ is suitable for angle-ply and cross-ply specimens in the individual data sets, while $m=\mathbf{3 0}$ is suitable for the unidirectional specimens. 

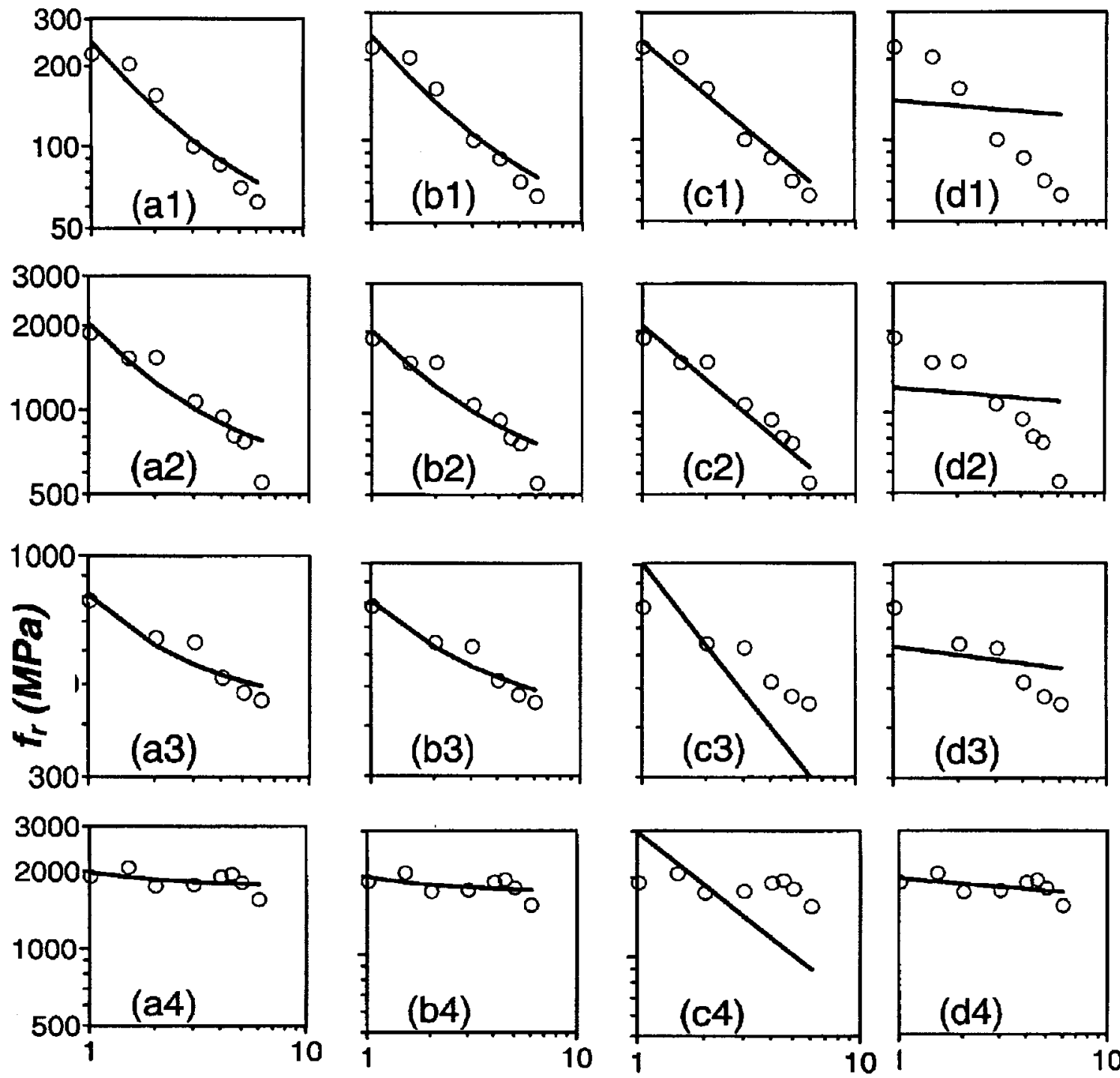

$D(\mathrm{~mm})$

Figure 5. Optimum fits of Jackson's [31] individual data sets by the formula used in Fig. 4 (numbers 1, 2, 3, 4 correspond to angle-ply, cross-ply, quasi-isotropic and unidirectional specimens presented in Fig. 4, and $a, b, c, d$ to the four plots in Fig. 4).

The individual fits corresponding to Fig. 4 are presented in Fig. 5. The fits of the available individual data sets using different size effect formulae (pure Weibull, pure energetic, energetic-statistical) can result in a deceptively straightforward conclusion: Because the plots of the data in the log-log scale look very close to straight lines, the pure Weibull-type formula might seem to be the best model, although the Weibull modulus ranges widely, from 3 to 35 (Figs. $5 \mathrm{c}$ and $5 \mathrm{~d}$ ). The reason is that both the deterministicenergetic and statistical-energetic formulae for very small and very large sizes contain straight segmnets in the log-log scale, and the optimization procedure automatically positions the straight segment on these data. As demonstrated by Bažant and Novák [39] for concrete, determination of the Weibull modulus from tests of such a limited size range is highly ambiguous and can yield widely ranging results. Instead of this approach, one must optimize the fit of the combination of all the available data in one plot while the value of Weibull modulus is forced to correspond to a common asymptotic value for very large sizes. In the 
energetic-statistical formula, the quasibrittle behavior implies a decrease of the modulus of rupture with the size, with the pure Weibull size effect of slope $-n_{d} / m$ approached asymptotically. Such a Weibull modulus may be called the asymptotic Weibull modulus (for sizes approaching infinity); its value is common for all the data sets. Then, in the overall plot of the data, the individual data sets are positioned according to the 'individual' apparent Weibull modulus (those with a small $m$ in the individual Weibull fit will be close to the small-size asymptote, those with a large $m$ will be close to the large-size asymptote of the overall combined size effect plot).

Since the available data are mainly limited to the range of small sizes, the iterative fitting procedure that was applied successfully for concrete [39] could not be applied here. Parameter $r$ and Weibull modulus $m$ (asymptotic), used in Fig.4 and Fig. 5(a,b), had to be estimated heuristically $(r=0.8$ and $m=35)$. This is of course a crude approximation in the present study. It can be overcome only after accumulating more experimental data, for a broader size range.

For the sake of illustration, Fig. 6 shows the energetic-statistical size effect for angle-ply specimens in the actual linear scales, calibrated from Jackson's [31] data.

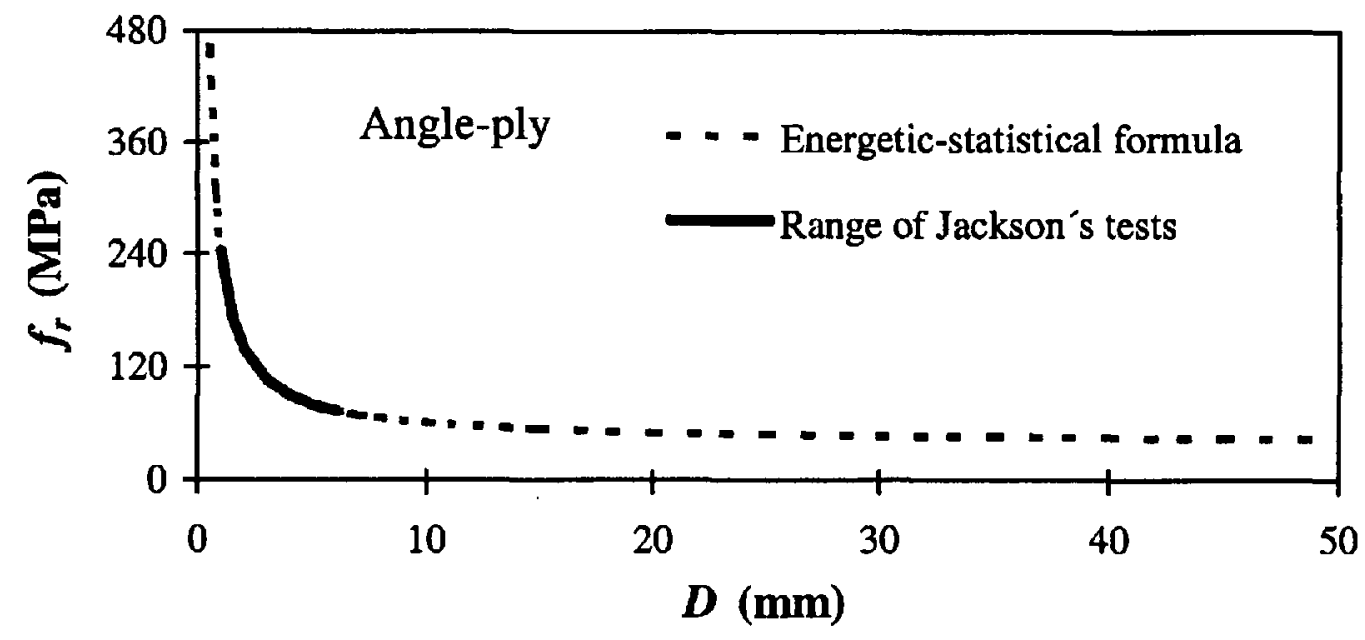

Fig. 6 Energetic-statistical formulae of Jackson's angle-ply data (actual scale).

It must be concluded that the size effect in Jackson's [31] tests was primarily deterministic energetic, caused by stress redistribution within the cross section of the laminate, with the corresponding energy release.

\section{Conclusions}

1. The failure of the basic components of sandwich structures, i.e., polymeric foam for the core and fiber laminate for the skins, have so far been treated according to the strength theory or plastic limit analysis, which exhibits no size effect, and all the size effects have been considered as purely statistical. The present analysis of experiments indicates that this current view may have to be fundamentally revised.

2. Although a polymeric foam with no large defects (cracks or notches) behaves essentially in a ductile manner, a foam that has suffered cracks or cracking bands, for instance due to impact, may behave in a very brittle manner and must be analyzed according to fracture mechanics.

3. The size effect on the flexural strength of laminates appears to be primarily energetic (deterministic) rather than statistical, except possibly for very large thicknesses for which the statistical size effect might also be significant. This further implies that fracture mechanics, rather than a strength criterion, needs to be used for evaluating the strength of laminates. 


\section{Acknowledgment}

Financial support under Grant ONR-N00014-91-J-1109 from the Office of Naval Research (monitored by Dr. Yapa D.S. Rajapakse) is gratefully acknowledged.

\section{References}

1. Bažant, Z.P., and Chen, E.P., Scaling of Structural Failure, Applied Mechanics Reviews ASME 50 (10), $593--$ 627; transl. in Advances in Mechanics (China) 29 (3), 383-433, 1997.

2. Bažant, Z.P., Size effect, International Joumal of Solids and Structures 37 (200), 69-80; special issue of invited review articles on Solid Mechanics edited by G.J. Dvorak for U.S. Nat. Corm. on Theor. and Appl. Mech., publ. as a book by Elsevier Science, Lid, 1999.

3. Bažant, Z.P., Size Effect on Structural Strength: A Review, Archives of Applied Mechanics (IngenieurArchiv, Springer Verlag) 69, 703-725 (75th Anniversary Issue), 1999.

4. Bažant, Z.P., Daniel, I.M., and Li, Zhengzhi, Size Effect and Fracture Characteristics of Composite Laminates, J. of Engrg. Materials and Technology ASME 118 (3), 317-324, 1996.

5. Bažant, Z.P., Kim, J.-J.H. Kim, Daniel, I.M., Becq-Giraudon, E., and Zi, Goangseup, Size Effect on Compression Strength of Fiber Composites Failing by Kink Band Propagation, Int. J. of Fracture 95, 103141 (special issue on Fracture Scaling, Z.P. Bazant and Y.D.S. Rajapakse, eds.), 1999.

6. Plantema, F.J., Sandwich Construction. John Wiley \& Sons, New York, 1996.

7. March, H.W., Effects of Shear Deformation in the Core of a Flat Rectangular Sandwich Panel - 1. Buckling under Compressive End Load, 2. Deflection under Uniform Transverse Load, U.S. Forest Products Laboratory Report 1583, 1948.

8. Reissner, E., The Effect of Transverse Shear Deformation on the Bending of Elastic Plates, J. Appl. Mech., Transactions of the ASME, Vol. 12, A69-A77, 1945.

9. Libove, C. and Batdorf S.B., A General Small-Deflection Theory for Flat Sandwich Plates, NACA TN IS26, 1948, also in NACA report899.

10. Hoff, N.J., Bending and Buckling of Rectangular Sandwich Plates, NACA TN 2225, 1950.

11. Mindlin, R.D., The Influence of Rotary Inertia and Shear on Flexual Motions of Isotropic Elastic Plates, $J$. Appl. Mech., Transactions of the ASME, Vol. 18, 31-38, 1951.

12. Zcnkert, D., Strength of Sandwich Beams with Interface Debonding, Compos. Struct., Vol. 17(4): 331-350, 1991.

13. Groth, H.L. and Zenkert D., Fracture of Defect Foam Core Sandwich Beams, J. Test Eval., Vol. 18(6): 390395, Nov 1990.

14. Gdoutos, E.E. and Daniel, I.M. and Wang, K.A., et al., Nonlinear Behavior of Composite Sandwich Beam in Three-point Bending, Exp. Mech., Vol. 41 (2): 182-189, Jun 2001.

15. Kutylowski, R. and Myslccki, K., Nonlinear-Theory of Sandwich Shells with Distinctly Soft Core, Z Angew. Math. Mech., Vol. 71(4):T302-T305 1991.

16. Das, Y.C. and Wallabhan, C.V.G., A Mathematical-Model for Nonlinear Stress-Analysis of Sandwich Plate Units, Math. Comput. Model 11:713-719 1988.

17. Kant, T., Kommineni J.R., Nonlinear-Analysis of Angle -Ply Composite and Sandwich Laminates, $J$. Aerospace Eng. 7(3): 342-352, Jul 1994.

18. Wu, J.C. and Pan, L.Z., Nonlinear Theory of Multilayer Sandwich Shell and its Application (I) - General Theory, Appl. Math. Mech.-Engl., Vol 18(1):19-27 Jan 1997.

19. Wu, J.C. and Pan, L.Z., Nonlinear Theory of Multilayer Sandwich Shell and its Application (II) Fundamental Equations for Orthotropic Shallow Shells, Appl. Math. Mech.-Engl., Vol 18(2):129-139 Feb 1997.

20. Wu, J.C. and Pan, L.Z., Nonlinear Theory of Multilaye Sandwich Shell and its Application (III) - Large Deflection and Postbuckling of Shallow Shells, Appl. Math Mech.-Engl., Vol 18(4):321-329 Apr 1997.

21. Triantafillou, T.C., and Gibson, L.J., Failure Mode Maps for Foam Core Sandwich Beams, Materials Science and Engineering, 95, 37-53, 1987.

22. Gibson, L.J., Modeling the Mechanical Behavior of Cellular Materials, Materials Science and Engineering, Al10, 1-36, 1989.

23. Gibson, L.J. and Ashby, M.F., The Mechanics of Three-Dimensional Cellular Solids, Proc. R. Soc. Lond, 382, 43. 1982.

24. Gibson, L.J. and Ashby, M.F., Cellular Solids: Structure and Properties, Pergamon Press (Oxford), 1997.

25. Bażant, Z.P., and Brocca, M., Failure of Foam Core Sandwiches: Numerical Simulation by Microplane Model, Mechanics of Sandwich Structure, (ASME Congress, Orlando), AMD-Vol. 245 (and AD-Vol. 62), Y.D. Rajapakse, G.A. Kardomateas and V. Birman, eds., Am. Soc. of Mech. Engrs., New York, 51-68, 2000.

26. Brocca, M., Bažant, Z.P., and Daniel. I.M., Microplane Model for Stiff Foams and Finite Element Analysis of Sandwich Failure by Core Indentation, Int. J. of Solids and Structures, in press. 
27. Bažant, Z.P. and Kazemi, M. T., Determination of fracture energy, process zone length and brittleness number from size effect, with application to rock and concrete, Int. J. of Fracture, 44, 111-131,1990.

28. Bažant, Z.P., and Planas, J., Fracture and Size Effect in Concrete and Other Quasibrittle Materials, CRC Press, Boca Raton and London, 1998.

29. Coturell, A.H., Iron and Stcel Institute Special Report 69, p. 281, 1963.

30. Wells, A.A., Unstable Crack Propagation in Metals-Cleavage and Fast Fracture, Symp. .on Crack Propagation, Cranfield, Vol. 1, 210-230, 1961.

31. Jackson, K.E., Scaling Effects in the Flexual Response and Failure of Composite Beams, ALAA Journal, Vol. 30 (8), 2099-2105, Aug 1992.

32. Sutherland, L.S., Shenoi, R.A. and Lewis, S. M., Size and Scale Effects in Composites: II. Unidirectional Laminates, Composites Sc.i.Technol., 59: 221-233, 1999.

33. Sutherland, L.S. and Shenoi, R.A., Lewis S. M., Size and Scale Effects in Composites: III. Woven-roving Laminates, Composiles Sci.Technol., 59: 235-251, 1999.

34. Weil, N.A. and Daniel, I.M., Analysis of the Fracture Probabilities in Nonuniformly Stressed Brittle Materials, J. Amer. Ceramic soc., 47(6): 268-274, 1964.

35. Wisnom, M.R., The Effect of Specimen Size on the Bending Strength of Unidirectional Carbon Fiber-Epoxy, Composite Structure, Vol. 18, 47-63, 1991.

36. Weibull, W., The Phenomenon of Rupture in Solids, Proc., Royal Swedish Institute of Engineering Research (Ingenioersvetenskaps Akad. Handl.) 153, Stockholm: 1-55, 1939.

37. Weibull, W., A Statistical Distribution Function of Wide Applicability, Journal of Applied Mechanics ASME, 18:293-297, 1951.

38. Bažant, Z.P. and Novák, D., Probabilistic Nonlocal Theory for Quasi-Brittle Fracture Initiation and Size Effect. I. Theory and II. Application, J. of Engrg. Mechanics ASCE 126(2): 166-174, 175-185, 2000.

39. Bažant, Z.P. and Novák, D., Energetic-Statistical Size Effect in Quasi-Brittle Failure at Crack Initiation, $\mathrm{ACl}$ Malerials Joumal, 97(3): 381-392, 2000.

40. Fisher, R.A. and Tippett, L.H.C., Limiting Frequency Distribution of the Largest and Smallest Member of a Sample, Proc. Cambridge Philosophical Society 24, 180-190, 1928.

41. Fréchet, M., Sur la loi de probabilité de l' écart maximum, Ann. soc. polon. math. 6, p.93, 1927

42. von Mises, P., La distribution de la plus grande de $n$ valeurs, Rev. math. union interbalcanique 1, p. $1,1936$.

43. Bažant, Z.P. and Li, Zhengzhi, Zero-Brittleness Size-Effect Method for One-Size Fracture Test of Concrete, J. of Engrg. Mechanics ASCE 122(5): 458-468, 1996.

44. Barenblatt, G. I., Similarity, Self-Similarity and Intermediate Asymptotics, Plenum Press, New York, 1979.

45. Bender, M.C. and Orszag, S.A., Advanced Mathematical Methods for Scientists and Engineers, McGraw Hill, New York (Chapter 9-11), 1978.

46. Hinch, Perturbation Methods, Cambridge University Press, Cambridge, UK, 1991

47. Bažant, Z.P., Scaling of Dislocation-Based Strain-Gradient Plasticity, Report No. 2000-12/C699s, Department of Civil Engrg. and Mater. Sci,. Northwestern University; J. of the Mechanics and Physics of Solids - in press.

48. Bażant, Z.P. and Li, Z., Modulus of Rupture: Size Effect due to Fracture Initiation in Boundary Layer, J. of Struct. Engrg. ASCE 121(4): 739-746, 1995.

49. Bažant, Z.P. and Cedolin, L., Stability of Structures: Elastic, Fracture and Damage Theories, Oxford University Press, New York, 1991.

50. Bažant, Z.P., and Skupin, L., Méthode d'essai de viellissement des plastiques renforcées sous contrainte (Testing Method for Aging of Reinforced Plastics Under Stress), Plastiques renforcées-Verre textile (Paris), 5, 27-30, 1967.

51. Bažant, Z.P., and Skupin, L., Material Properties for the Design of Polyvinylchloride Structural Members (in Czech), Plastické Hmoty a Kaucukk, 5, 161-166, 1968. 